\title{
Activated Paphia undulate Shells Waste (APSW): A Cost-Effective Catalyst for Biodiesel Synthesis from Rubber and Jatropha curcas Seeds Oil (RSOME \& JSOME)
}

\author{
Said Nurdin, Fatimah A. Misebah, Siti F. Haron, Nur S. Ghazali, Rosli M. Yunus, and Jolius Gimbun
}

\begin{abstract}
The Paphia undulata shell, which is available in abundance, has no any further processing for value-added materials and is commonly discarded as solid waste, was used as solid catalyst in a transesterification reaction to synthesize biodiesel from Rubber and Jatropha curcas seeds oil (RSOME and JSOME). The biodiesel non-vegetable oil feedstock and catalyst were prepared, characterized, activated and analyzed using GC, FESEM, BET, DTA-TGA, XRF and FTIR analysis. The activated Paphia undulata shells waste (APSW) had a maximum surface area of $2.1290 \mathrm{~m}^{2} / \mathrm{g}$, diameters of $17-3000 \AA$, pores adsorption and desorption cumulative volume were $0.006841 \mathrm{~cm}^{3} / \mathrm{g}$ and $0.006928 \mathrm{~cm}^{3} / \mathrm{g}$ with the pores size of 312.527 $\AA$, and it reflected the composition of 83.99-86.25\% calcium oxide, etc. The resulted Rubber and Jatropha seeds oil biodiesel yields of $75.93 \%$ and $93.33 \%$ were found by the methanol/oil ratio of $6: 1$, catalyst amount of 4 wt.\%, temperature of $60{ }^{\circ} \mathrm{C}$ and reaction time of 3 hours. The synthesized biodiesels were approved by GC-MS, and its properties fulfills the limitation of specification described by ASTM D6751.
\end{abstract}

Index Terms-Transesterification, Paphia undulata shells, Rubber and Jatropha oil, biodiesel.

\section{INTRODUCTION}

The shell wastes of Paphia undulata were commonly casted away on the restaurants, food and canneries industry in Malaysia without any eminent utilization for valuable products. Estimated potential annual production is 20,000 MT, and it has been steadily increasing since the 1990 s to reach a new record of 13.6 million metric tonnes in 2005 . Utilization of the heterogeneous catalyst such as Paphia undulata shell for biodiesel does not produce soap through free fatty acid neutralization and triglyceride saponification. Otherwise, the use of metal catalysts for biodiesel synthesis from edible sources like palm oil, soybean, etc. which are consumed as food creates versus fuel dilemma and expensive, thus this work aims to circumvent this issues by using the activated Paphia undulata shells waste (APSW) for Rubber and Jatropha curcas oil transesterification to biodiesel

Manuscript received March 10, 2014; revised May 6, 2014. This work was supported in part by the Malaysia Education Ministry under Grant RACE-KPM- RDU 141303.

Said Nurdin, Rosli M. Yunus, Fatimah A. Misebah, Siti F. Haron, and Nur S. Ghazali are with the Chemical Engineering Dept., Faculty of Chemical and Natural Resources Engineering, University of Malaysia Pahang (UMP), Lebuh Raya Tun Razak, 26300 Gambang, Kuantan, Pahang, Malaysia (e-mail: snurdin2@gmail.com, azzahra_1210@yahoo.com).

Jolius Gimbun is with the Cariff, University of Malaysia Pahang (UMP), Lebuh Raya Tun Razak, 26300 Gambang, Kuantan, Pahang, Malaysia (e-mail: jolius@ump.edu.my).
(RSOME \& JSOME). Biodiesel synthesis using $\mathrm{CaO}$ base catalyst has some advantages such as higher activity, mild reaction condition and low cost.

The Rubber and Jatropha based biodiesel offers an alternative feedstock due to the total land area of Malaysia rubber plantation about 1,229,940 hectares which resulted about $355,200,000 \mathrm{~kg}$ fat and 136,800,000 kg protein waste per year from rubber seeds, and the Jatropha plantation was 1.5 million acres in year 2009 and 2.5 million acres in 2010, and it could be increased yearly. These potential raw materials, catalyst and methods could be a promising process technology for biodiesel synthesis. Biodiesel known as an alternative and renewable energy for diesel engine that more biodegradable, non-toxic and low emission of $\mathrm{CO}_{2}$ compared to petroleum diesel [1]. It's also chemically known as long chain of fatty acid methyl ester that produced from various vegetables oil. Synthesis of biodiesel is by reaction of triglyceride and alcohol in the transesterification process [2][3]. According to [4], the fluctuation price of biodiesel in market contributes from the used raw material. Thus, there has been depressing needs in finding new feedstock sources and more economical. The feedstock from the vegetables oils become a resources in the production biodiesel due to its renewable and eco-friendly, and also have excellent properties. Vegetables oil as raw material in the methyl ester synthesis is able to alleviate the production carbon dioxide in atmosphere where nowadays it is major worldwide environmental problem.

Basically, the vegetables oil is divided into two types that is edible oil that able to being eaten as food such as coconut oil, soybean, and sunflower [5]. This type of oil was come up with an issue where it disturbes human food chain when applied as raw material during biodiesel production. Meanwhile, non-edible oil is oil that unable to use as food source such as Jatropha, castor, karanja oil and others. This oil has high potential to be used as raw material. The rubber seed (heveabrasiliensis) oil contains high unsaturated fatty acid $(80 \%)$, it can be realized in the transesterification process for biodiesel synthesis. Rubber seed has widely mixture of chemical composition such as fat, protein and other mineral that has potential to be used in a number of applications such as biodiesel, biolubricant and feed for animals [6].The world producers of natural rubber are Thailand (35\%), Indonesia (23\%), Malaysia (12\%), India (9\%) and China (7\%) [7]. During 2009, the rubber plantation area in Malaysia has been growing up to 1.2 million hectares and there were abundance of rubber seeds could be found [8]. On the other hands, Jatropha curcas belongs to Euphorbiaceae family that known 
as Jarak Pagar in Malaysia was commonly found in tropical country and sub-tropical country in the world such as Malaysia, Indonesia, Hong Kong and India [9]. Thus, availability of Jatropha oil as raw material can help to reduce price of biodiesel at international market that influenced from the raw material cost and human food chain disturbance. The Jatropha oil has also the potential to be used as feedstock in the biodiesel and biolubricant synthesis due to high unsaturated fatty acid content [10].

The developement of heterogeneous catalyst as alternative heterogeneous catalyst such as metallic or metal oxide has wide potential to be utilized where these catalyst can be recycled easily [11]. Beside that, its much cheaper than enzyme or other biochemical catalyst. Currently, the transesterification process of biodiesel using solid base heterogeneous calayst such as calcium oxide that derived from mollusk shells has been investigating continously [12], [13]. The important reason is a new solid base heterogeneous should be developed due to their ablity for yield improvement at lower temperature, shorter time and easy in separation process [14]. The Paphia undulata has been supporting offshore of Malaysia since 1970, where the shell can be developed as solid base catalyst for biodiesel synthesis.

Unfortunately, the oil or fat of alkaline transesterification process should be not more than $1 \%$ of free fatty acid (FFA) content. The FFA level that above this threshold level, saponification will take place and results the yield decrease of methyl ester. Thus, there is an alternative suggestion by applying two-step process of esterification and transesterification for biodiesel and biolubricant production from high fatty acid oil [10], such as Jatropha and rubber seeds oil. This two step process application can be expected a high yield of biodiesel synthesis.

\section{MATERIALS AND METHODS}

\section{A. Materials}

The Papia undulata shells waste was collected from resturants and food processing industries, Kuantan, Pahang. The Jatropha curcas oil, was procured from Bionas Sdn Bhd. Kuala Lumpur. The Rubber seeds were provided by RISDA rubber plantation, Selangor, Malaysia. Methanol, hydrocloric acid and hexane (GC grade) were purchased from Chemmart Asia Sdn Bhd.

\section{B. Methods}

The used rubber seed of $20 \mathrm{~kg}$ was dried in the oven at $100^{\circ} \mathrm{C}$ for 4 hours. The dried rubber seed was decorticated manually from the kernel shell. Then, the kernel were milled based on the particles size for an average diameter $1 \mathrm{~mm}$ for extraction. The used microwave assisted extraction is shown in Fig.1. Then, the rubber seed of $10 \mathrm{~g}$ was placed in $250 \mathrm{ml}$ extraction flask with $100 \mathrm{ml}$ of $\mathrm{n}$-hexane as solvent. The microwave assisted extraction of rubber seeds oil was operated by $150 \mathrm{~W}$ for about 15 minutes with 5 minutes interval for cooling. The hexane-oil mixture was evaporated using rotary evaporator. The oil was then collected and centrifuged at $1000 \mathrm{rpm}$ for 5 minutes for oil separation from other particles. The gas chromatography (GC) was used for fatty acid analysis. Next, the Papia undulata shells was washed using clean water and dried at $100^{\circ} \mathrm{C}$ for overnight. Then, the solid catalysts was crushed and calcinated in the furnace at $680^{\circ} \mathrm{C}$ for 2 hours. The catalyst was removed from the furnace and kept in desiccators to prevent the air contact. Finally, the raw material (Papia undulata shells) and the solid catalyst were characterized using several methods such as Field Emission Scanning Electron Microscopy (FESEM), X-Ray Florescence (XRF), Fourier Transformed Infra Red (FTIR) Spectroscopy, Brunauer- Emmett-Teller (BET) and Differential Thermal and Thermo-Gravimetric Analysis (DTA-TGA).

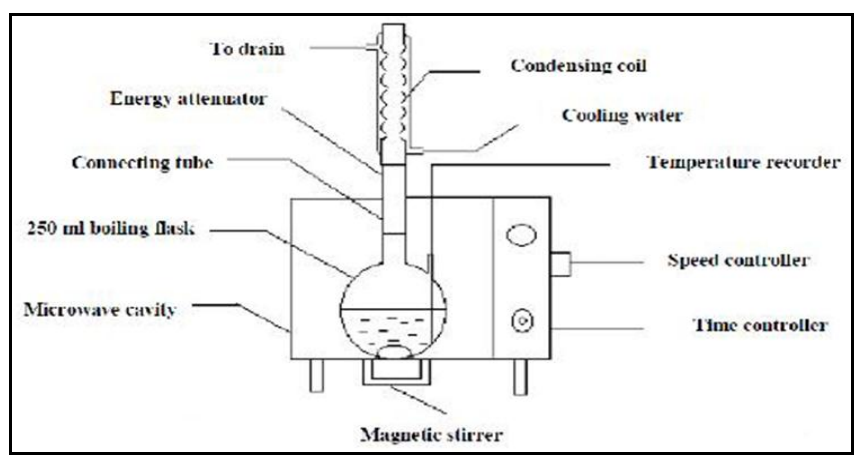

Fig. 1. Microwave assisted extraction of rubber seed oil.

The bench scale set-up for synthesis of Rubber seed oil methyl ester (RSOME) and Jathropha seed oil methyl ester (JSOME) was illustrated in Fig. 2. It consists of a round bottom flask reactor that placed in an adjusted temperature water bath. Firstly, acid pre-treatment process was applied to reduce level of free fatty acid. The oil was placed in two neck flask equipped with magnetic stirrer and condenser that used as cooling system to prevent alcoholic loss. Then, the catalyst solution (a specified amount of $\mathrm{HCl}$ with $1 \% \mathrm{w} / \mathrm{w}$ of oil was dissolved in methanol at molar ratio of 6:1 methanol to oil) was poured into flask. The mixture was heated up to $60{ }^{\circ} \mathrm{C}$ for about 3 hour with constant stirrer. After finishing, the mixture was placed in separating funnel for few hours to separate excess methanol. The excess methanol with $\mathrm{HCl}$ and impurities moves to the top surface and removed. Meanwhile, the lower layer was collected and continued with base transesterification process. The transesterification process as the second step was run using the heterogeneous catalyst from the Papia undulata shells waste.

For the optimization reactions of RSOME and JSOME synthesis, the experiment was conducted at various temperature levels $\left(45\right.$ to $65^{\circ} \mathrm{C}$ ), amount of catalyst ( 1 to $5 \%$ $\mathrm{w} / \mathrm{w}$ ) and time of reaction ( 1 to $5 \mathrm{~h}$ ). After final separation, the catalyst with other debris remains accumulated in the bottom layer, meanwhile the upper layer known as RSOME and JSOME was collected and washed using warm water $\left(50^{\circ} \mathrm{C}\right)$. The washing process was repeated until the water become clear and the methyl ester production was placed on the rotary evaporator for excess methanol removal by heating up to $75^{\circ} \mathrm{C}$ with the time of 30 minutes.

The analysis of RSOME and JSOME were performed using Gas Chromatography Masspec (GC-MS). The sample was prepared in $2 \mathrm{ml}$ vial with $0.02 \mathrm{ml}$, it was mixed with 
$1.980 \mathrm{ml}$ of hexane (GC grade). For this purpose, GC-MS (Agilent GC) with the helium gas by the injector temperature of $200{ }^{\circ} \mathrm{C}$ at split ratio of $30 \mathrm{ml} / \mathrm{min}$ was set up.

The initial oven of $70^{\circ} \mathrm{C}$ with the hold temperature at 3 minutes was set up. After the condition with the isothermal, the oven temperature was increased up to $230^{\circ} \mathrm{C}$ at heating rate $7^{\circ} \mathrm{C} / \mathrm{min}$. This operation condition was run for enhancement biodiesel yield. The yield of biodiesel was calculated by the following formula (refer to "(1)").

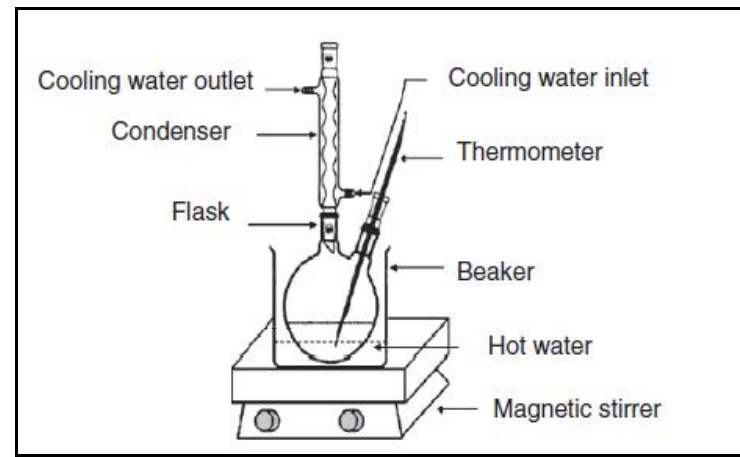

Fig. 2. The experimental setup for the RSOME and JSOME synthesis.

$$
\text { Biodiesel Yield }(\%)=\frac{\text { Biodiesel mass } \times \text { Purity }}{\text { Mass of used oil }}
$$

where biodiesel mass (g), mass of used oil (g), and purity (\%) is methyl ester composition from GC analysis.

\section{RESULT AND DISCUSSION}

\section{A. Field Emission Scanning Electron Microscopy (FESEM)of Papia undulata Shells}

The surface morphology of catalyst from Papia undulata shells was analyzed by FESEM. Fig. 3(a) shows that the surface of catalyst before activated is rough and disordered surface with low porosity structure compared after activation process. Otherwise, Fig. 3(b) illustrates a relatively smooth with spherical particles of porous structure. The porous structure is fast similar to the another calcined mollusk shells, like cockle shells, etc. [15]. This invention verify that the grain shapes are almost spherical and grain-neck growth due to the thermal decomposition.

\section{B. X-Ray Florescene (XRF) of Activated Paphia undulata Shells}

The detailed chemical composition of the solid catalyst from Paphia undulata shells waste using X-ray florescene (XRF) shown in Table I. It indicates that a significant $\mathrm{CaO}$ content of $86.25 \%$ with small amount of other compounds like $\mathrm{Na}_{2} \mathrm{O}, \mathrm{SrO}, \mathrm{MgO}, \mathrm{SO}_{3}, \mathrm{Cl}$, etc. The minor constituents plays not so important role, but the major component of calcium oxide as heterogenous catalyst has mainly contibuted for biodiesel synthesis. The calcium oxide can be resulted also from calcination of Pomeca sp. shell, etc. for transesterification process [12].

C. Differential Thermal Analysis and Thermo-Gravimetric Analysis (DTA-TGA) of Paphia undulata Shells

The waste shell was analyzed using DTA-TGA to determine the suitable calcination temperature during the catalyst preparation for transesterification process that shown in Fig. 4. From the TGA graph, it reflects that $41.76 \%$ weight loss is observed on the samples at temperature range 610 to $760{ }^{\circ} \mathrm{C}$. If the temperature is higher than $760{ }^{\circ} \mathrm{C}$, the weight loss is remain almost constant and become ash. Meanwhile from the DTA curve, maximum temperature is found around 600 to $770^{\circ} \mathrm{C}$. From this with taking account the preparation time and energy consumption, the temperature is selected to produce the $\mathrm{CaO}$ from the Paphia undulata shell at $680^{\circ} \mathrm{C}$.
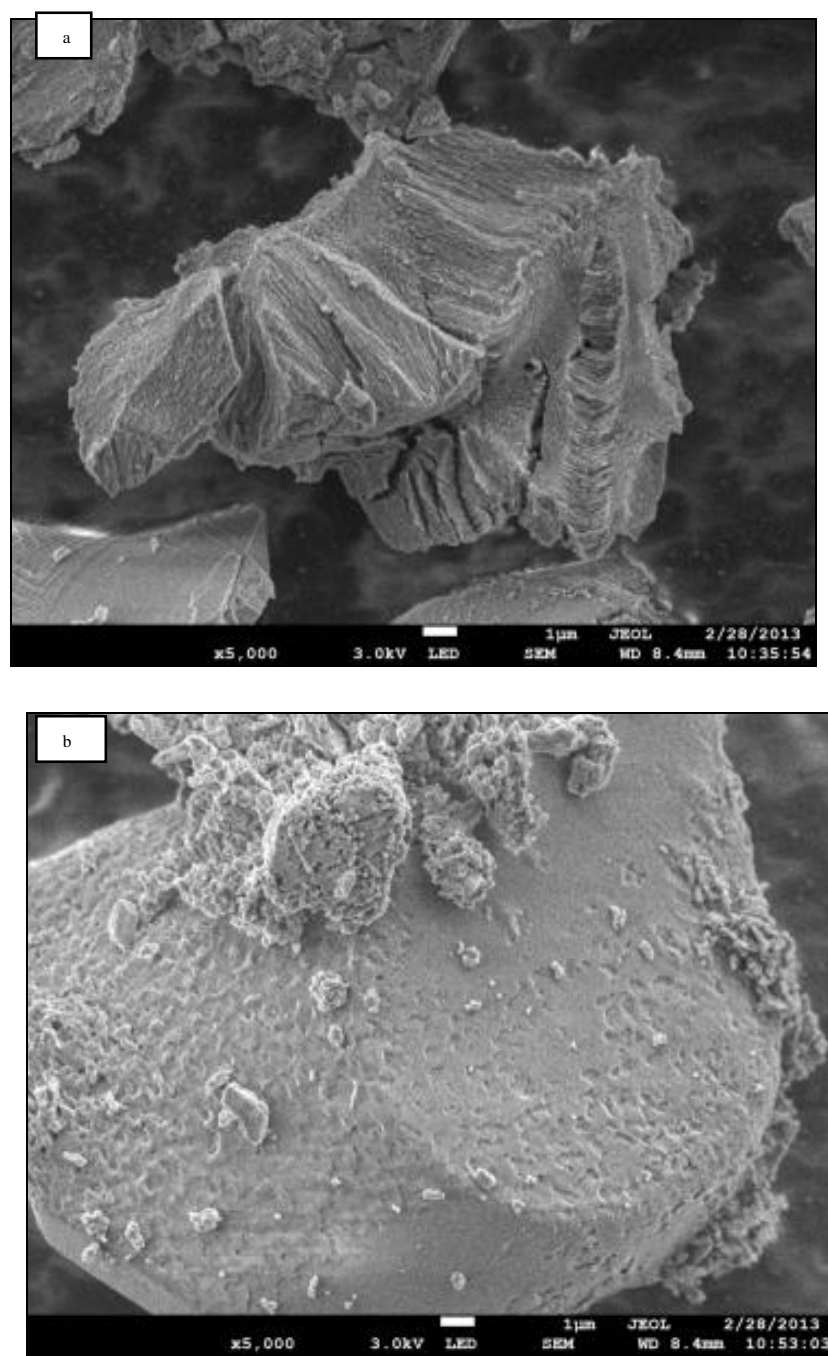

Fig. 3. FESEM micrograph of Paphia undulata shells at 5,000 x, prior to activation (a), post-activation (b).

\begin{tabular}{|c|c|}
\hline Composition & Weight (\%) \\
\hline $\mathrm{CaO}$ & 86.2 \\
\hline $\mathrm{Na}_{2} \mathrm{O}$ & 1.54 \\
\hline $\mathrm{SrO}$ & 0.29 \\
\hline $\mathrm{MgO}$ & 0.17 \\
\hline $\mathrm{SO}_{3}$ & 0.15 \\
\hline $\mathrm{Cl}$ & 0.07 \\
\hline $\mathrm{Fe}_{2} \mathrm{O}_{3}$ & 0.06 \\
\hline $\mathrm{P}_{2} \mathrm{O}_{5}$ & 0.06 \\
\hline $\mathrm{SiO}_{2}$ & 0.05 \\
\hline $\mathrm{K}_{2} \mathrm{O}$ & 0.03 \\
\hline $\mathrm{Al}_{2} \mathrm{O}_{3}$ & 0.03 \\
\hline
\end{tabular}

\section{Brunauer-Emmett-Teller (BET) of Paphia undulata} Shells

The major roles in catalyst activity are the specific surface 
area and active sites. The BET analysis gave the surface area of Paphia undulata shells from $0.9482 \mathrm{~m}^{2} / \mathrm{g}$ before calcinations process and after calcination increases up to $2.1290 \mathrm{~m}^{2} / \mathrm{g}$. It is reported that the surface area of calcined cockle shell is $1.56 \mathrm{~m}^{2} / \mathrm{g}$ which much lower than calcined Papia undulata shells [15]. These results prove that the calcinations process increases the sites of catalyst activity.

\section{E. Fourier Transformed Infra Red ( FTIR) Spectroscopy of} Paphia undulata Shells

The FTIR spectra of both Papia undulata shell before and after calcination was conducted based on the last experiments principles [12]. In this invention, the $\mathrm{OH}^{-}$band was observed at $3643.23 \mathrm{~cm}^{-1}$. The results shown in Fig. 5 and 6 . The major peak of $\mathrm{CaCO}_{3}$ in the uncalcined catalyst occures at 1471 , 856 and $712 \mathrm{~cm}^{-1}$. Meanwhile after calcination major band takes place at 1471.05876 .42 and $558.07 \mathrm{~cm}^{-1}$.

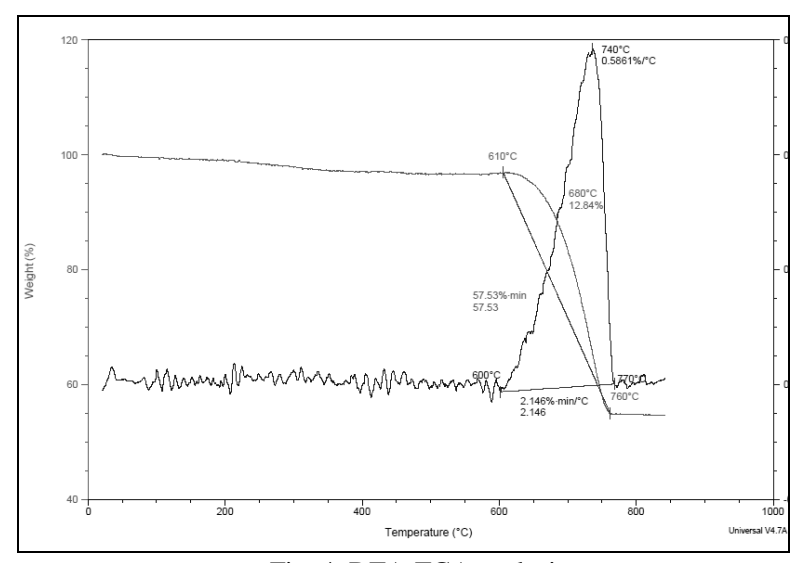

Fig. 4. DTA-TGA analysis.

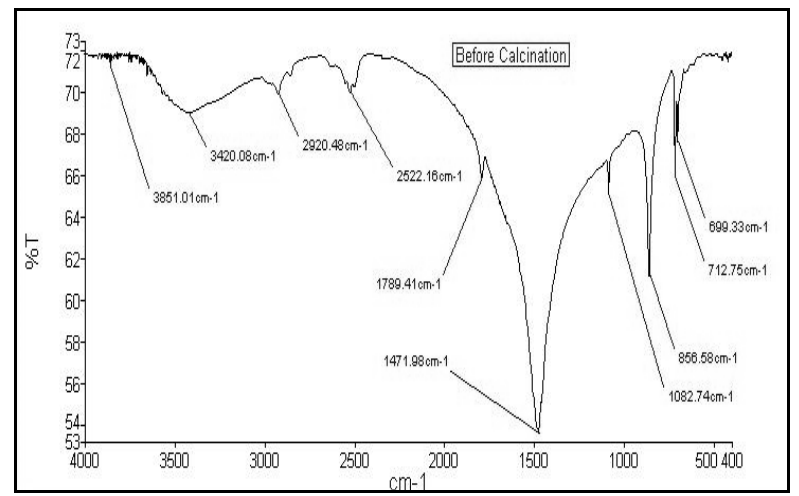

Fig. 5. FTIR of uncalcined Papia undulata shells catalyst.

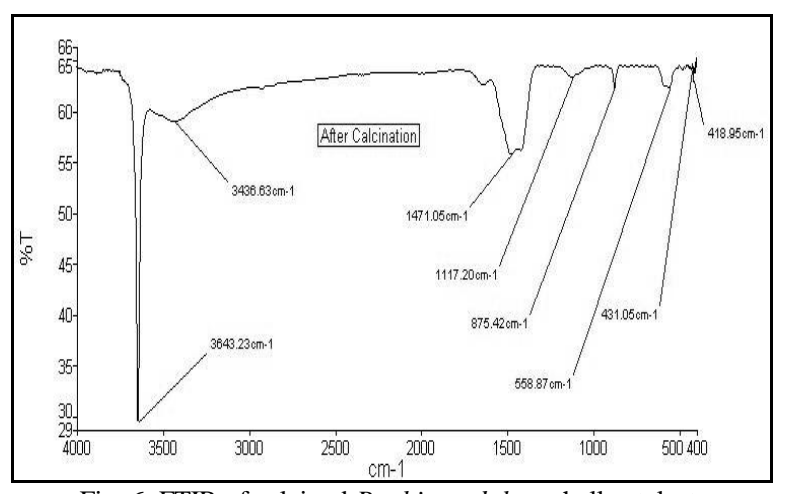

Fig. 6. FTIR of calcined Paphia undulata shell catalyst.

\section{F. Recyclability of Activated Paphia undulata Shells}

The prepared catalyst is able to be recycled at least five times, with a biodiesel yield nearly $73.52 \%$ and $90 \%$ for RSOME and JSOME (Fig. 7). Before reuse, the spent catalyst was washed with methanol and n-hexane to remove the adsorbed materials. After being used more than five times, the performance of activated Paphia undulata shells waste derived catalyst descended gradually. The activation of Paphia undulata shell catalyst could be ascribed to its structure change. The structure change of catalyst might be resulted from the reactants (Rubber and Jatropha seeds oil with hydroxyl group and methanol) contain a little amount of water. However, the heterogenous catalyst is proved to be stable, it can be reused and regenerated by simple calcination for biodiesel synthesis [16]-[18].

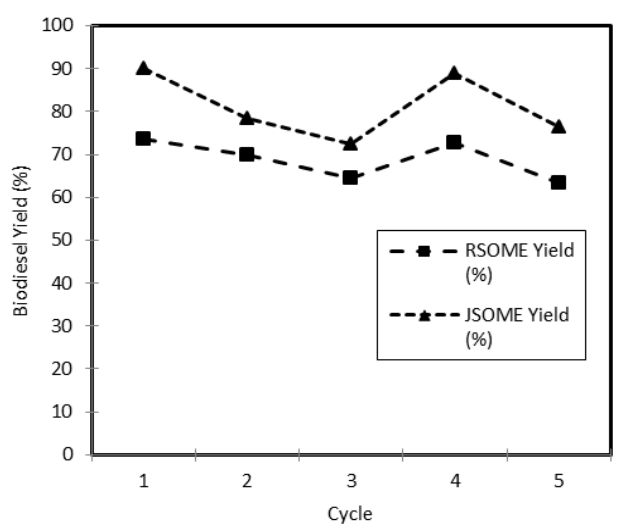

Fig. 7. Effect of catalyst recyclability on the biodiesel yield.

\section{G. Effect of Catalyst Loading on the Biodiesel Yield}

The catalyst plays a crucial role to create an alternative pathway of reaction besides tendency to lower the activation energy for reaction of molecules reactant [16]. Fig. 8 shown the increase of catalyst amount, also the improvement of biodiesel yield, and the maximum yield of JSOME and RSOME is achieved at $4 \% \mathrm{w} / \mathrm{w}$ catalyst loading. This result is supported by [12] that the obtained optimum biodiesel yield also by using $4 \% \mathrm{w} / \mathrm{w}$ calcium oxide.

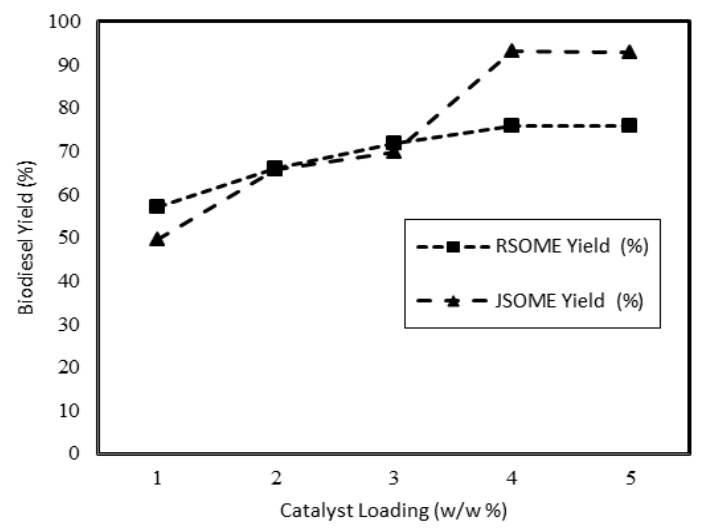

Fig. 8. Effect of catalyst loading on the biodiesel yield.

The $\mathrm{CaO}$ basic site tendency to transform alcohol group into nucleophile molecule that more active and attach carbonyl group in triglyceride to form alkyl ester and glycerol. If refer to the Fig. 8, the optimum catalyst is higher than loading point, the yield of biodiesel descends. The amount of ester yield is slightly with the increase of amount base catalyst that used $\mathrm{KOH}$ due to formation of high soap in the product. Thus, the optimum catalyst loading for tranesterification of Rubber and Jatropha seeds oil is reflected at $4 \% \mathrm{w} / \mathrm{w}$ 
activated Papia undulata shells waste.

\section{H. Effect of Time on the Biodiesel Yield}

The influence of reaction time on the RSOME and JSOME yield was observed at the temperature of $60^{\circ} \mathrm{C}$ with the methanol to oil ratio of $6: 1$ and $4 \%$ w/w catalyst loading. Fig. 9 reflects that the optimum transesterification time for RSOME and JSOME yields are obtained at 3 hours. At first few hours of reaction time, the reaction is in slow rate due to dispersion of interaction between molecules still in progress [16]-[18]. Above than that point, the yield decreases slightly from $75.93 \%$ to $75 \%$ for RSOME and $93.33 \%$ to $91.09 \%$ for JSOME (Fig. 9).The yield reduction of biodiesel synthesis is due to backward reaction which causes more soap formation.

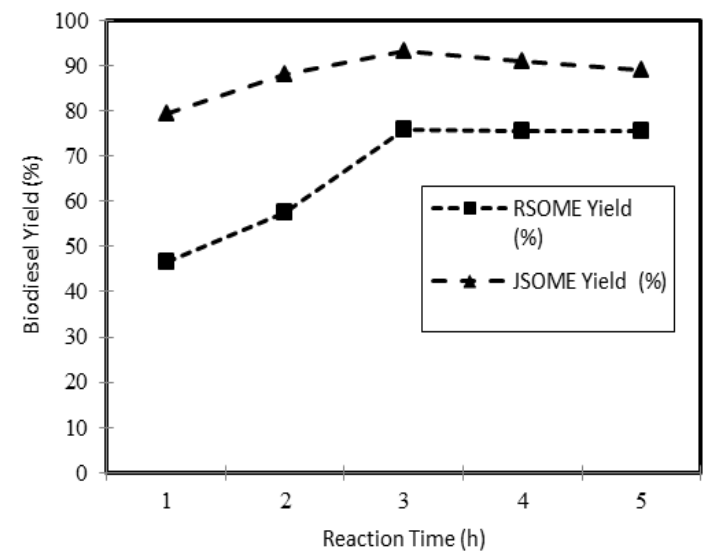

Fig. 9. Effect of time on the biodiesel yield.

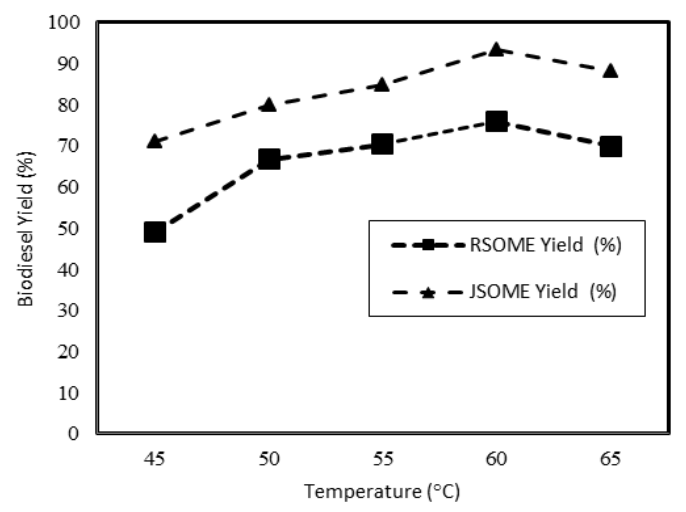

Fig. 10. Effect of temperature on the biodiesel yield.

\section{Effect of Temperature on the Biodiesel Yield}

The effect of temperature on the RSOME and JSOME synthesis was tested by the methanol to oil ratio 6 to 1 with 3 hours of reaction time and $4 \% \mathrm{w} / \mathrm{w}$ (catalyst/oil weight ratio). Another catalyst, like egg shell waste has been approved for biodiesel synthesis from non-vegetables oil by various temperatures [16]. By the maximum temperature of $60^{\circ} \mathrm{C}$ gives the maximum yield of RSOME and JSOME are $75.93 \%$ and $93.33 \%$ (Fig. 10). The yield of RSOME and JSOME decreases slightly above this temperature. The high temperature is able to supply sufficient energy for collision between reactant molecules that promote towards maximum reaction. Unfortunately, above $60^{\circ} \mathrm{C}$ favorable tends to accelerate the saponification of the triglyceride before completion of the transesterification process. The process condition of $60{ }^{\circ} \mathrm{C}$ has also been obtained for biodiesel synthesis from waste frying oil through two-step catalyzed process using methanol [17]. The use of methanol for transesterification of soybean oil has also been done under batch condition [18]. As the temperature was more than the methanol boiling point $\left(64.7^{\circ} \mathrm{C}\right)$, the biodiesel yield decreased due to vaporization. The percentage yield of RSOME is slightly lower than JSOME. The optimum temperature for biodiesel synthesis is depends on the fat and the oil used. Thus, this invention shows that RSOME and JSOME shares with the same optimum temperature of $60^{\circ} \mathrm{C}$, but the different synthesis yield due to fatty acid content.

\section{CONCLUSION}

The activated Paphia undulata shells waste can be utilized as a cost-effective catalyst for biodiesel synthesis from non-vegetable oil. The characterization and analysis results of activated catalyst shown a large surface area compared non-activated catalyst. The catalyst weight loss after activation occurred $41.72 \%$ at temperature of $680{ }^{\circ} \mathrm{C}$, and it causes the chemical structure and composition change of the catalyst. The calcined catalyst gave the maximum calcium oxide of $86.25 \%$. This activated catalyst containing high calcium oxide exhibited a good performance in synthezing biodiesel. The highest biodiesel yield $(75.93 \%$ of RSOME and nearly $93.33 \%$ for JSOME) was observed at temperature of $60{ }^{\circ} \mathrm{C}$ by catalyst addition of 4 wt.\% to a mixture of methanol-oil ratio of $6: 1$ via batch system for 3 hours. Besides that, the catalyst still maintained the activity and crystalline phase after being reused 5 cycles, and it had high recyclability up to $73.52 \%$ and $90 \%$ for RSOME and JSOME. The resulted JSOME and RSOME properties fulfills the limitation of biodiesel specification, and the biodiesel yield can be improved by the development of various another process parameters, like methanol-non edible oils mixture ratio, etc. and heterogenous catalysts via the multi-step purification process.

\section{REFERENCES}

[1] K. Watcharathamrongkul, B. Jongsamjit, and M. Phisalaphong, "Calcium oxide based catalysts for ethanolysis of soybean," Songklanakarin Journal Science Technology, vol. 32, no. 6, pp. 627-634, 2010.

[2] U. Rashid, F. Anwar., A. Jamil, and H. N. Bhatti, "Jatropha curcas seed oil as a viable source for biodiesel," Pakistans Journal Bot., vol. 42, no. 1, pp. 575-582, 2010.

[3] P. L. Boey, G. P. Maniam, and S. A. Hamid, "Performance of calcium oxide as a heteregenous catalyst in bidiesel production: A review," Chemical Engineering Journal, vol. 168, pp. 15-22, 2011.

[4] D. Krishnan and D. M. Dass, "The kinetics study of biodiesel in waste cooking oil," Journal of Biotechnology, vol. 11, no. 41, pp. 9797-9804, 2012.

[5] A.K. Jain and A. Suhane, "Capability of biolubricants as alternative lubricant for industrial and maintainance applications," International Journal of Current Engineering and Technology, vol. 3, no. 1, pp. 179-183, 2013.

[6] J. Salimon and A. A. Ishak, "Optimization process for esterification of rubber seed oil (RSO) with Trimethylolpropane (TMP),"Journal of Science and Technology, vol. 4, pp. 81-90, 2012.

[7] S. S. Kumar and K. Purushothaman, "High FFA rubber seed oil as an alternative fuel for diesel engine, an overview," International Journal of Engineering and Science, vol. 1, no. 10, pp. 2278-4721, 2012.

[8] S. H. A. Halim, Biopetrol Synthesized from Rubber Seed Oil Through Heterogeneous Catalytic Cracking Using Kaolinite as Catalyst. Bsc. 
Hons degree thesis, Universiti Malaysia Pahang, Gambang, Kuantan, Pahang, 2010.

[9] R. K. Singh and S. K. Padhi, "Characterization of jatropha oil for the preparation of biodiesel," Natural Product Radiance, vol. 8, no. 2, pp. 127-132, 2009

[10] N. H. Arbain and J. Salimon, "Synthesis and characterization of ester trimethylolpropane based jatropha curcas oil as biolubricant based stocks," Journal of Science and Technology, vol. 2, no. 2, pp. 47-58, 2010.

[11] R. J. Li., L. Chen, and Z. C. Yan, "Synthesis of TMP ester of oleic acid using a multi- $\mathrm{SO}_{3} \mathrm{H}$-Functionalized ionic liquid as an efficient catalyst," Journal of AOCS, vol. 89, pp. 705-711, 2012.

[12] Y. T. Margaretha, H. S. Prastyo, A. Ayucitra, and S. Ismadji, "Calcium oxide from Pomeca sp. shell as a catalyst for biodiesel production," International Journal of Energy and Environmental Engineering, vol. 3, no. 33, pp. 1-9, 2012.

[13] A. Birla, B. Singh, S. N. Upadhyay, and Y. C. Sharma, "Kinetics studies of synthesis of biodiesel from waste frying oil using a heterogeneous catalyst derived from snail shell," Journal of Bioresource Technology, vol. 106, pp. 95-100, 2012.

[14] F. Guo and Z. Fang, "Biodiesel production with solid catalysts, biodiesel-feedstocks and processing technologies," in Tech Europe, Rijeka, pp. 345-350, 2011

[15] N. A. Rashidi and S. Yusup, "A study of calcinations and carbonation of cockle shell," World Academy of Science, Engineering and Technology, vol. 60, pp. 818-823, 2011.

[16] S. Nurdin, J. Gimbun, R. Abdullah, N. S. Ghazali, L. A. Shah, and N. F. Omar, "Biodiesel synthesis from castor oil using egg shell waste as solid catalyst" presented at the ICBBVAP, Kuala Lumpur, October 23-24, 2012.

[17] M. Charoenchaitrakool and J. Thienmethangkoo, "Statistical optimization for biodiesel production from waste frying oil through two-step catalyzed process," Fuel Processing Technology, vol. 92, pp. $112-118,2011$

[18] W. Xie and L. Zhao, "Production of biodiesel by transesterification of soybean oil using calcium supported tin oxides as heteregenous catalyst," Energy Conversion and Management, vol. 76, pp. 55-62, 2013.

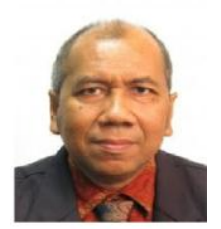

Said Nurdin received his B.Sc. Eng. in chemical engineering from Institute of Sepuluh Nopember Technology (ITS), Surabaya, Indonesia, and his Ph.D from the University of Paderborn, Paderborn, Germany. His experience includes serving as a researcher, consultant and manager for environment, energy and chemical processing industries, word agency (UNDP, etc.), government and NGO's in Indonesia, Malaysia and Germany. He has been a senior lecturer, laboratory head, PIC of research development acceleration, chair of environment and management division for under-and post-graduate program at Chemical Engineering Dept., Faculty of Engineering and Research Institution of Syiah Kuala University, Banda Aceh, Indonesia. Beside a senior lecturer, he has appointed as head of academic panel and research group for environment and process safety at the Faculty Of Chemical and Natural Resources Engineering, University Malaysia Pahang, Gambang, Kuantan, Malaysia. Nurdin has also designed as Trainer for Chemical Industries Staff in Aceh and BASF Gebeng, Kuantan, Pahang. He has authored more than 30 articles and 7 training manuals as author, co-author, or editor on chemical processing, environment and energy. The current research interests in the field of environmental chemical and biochemical process engineering (water and wastewater treatment, solid, hazardous and medical waste management, air pollution), catalysts and kinetics, separation technology, biolubricant, biomass and biofuel energy, and biofertilizer.

Dr. Ir. Nurdin has been a member of DECHEMA e. V. Frankfurt a. M, and nowadays he is the membership in the professional societies of IE A Aceh, EPW Jakarta, Environment Club (EC), W. P. Putrajaya, and IChemE (Inst. of Chem. Eng.)(In The Affiliation Process). Kuala Lumpur-London. He also gives interviews for television, newspaper, and radio talkshow about the international matters that face the industry, environment and energy. This active speaker and exhibitor is the recipient of several awards, including listing Bioinnovation Award, Silver Medal, BioMalaysia, 2011, Merit Award: Research Product Category, UMP, 2012 and2013, Kuantan. Gold Medal: INPEX 2012, Pittsburgh, PA. Gold Medal: IID, 2012, Terengganu. Gold Medal: MUCET 2012, Perlis. Silver Medal: MTE 2013, Kuala Lumpur. Gold Medal: 3; Silver: 5: CITREX 2013\&2014, Kuantan. Silver: WaterInno,WM, 2013, KL. Gold Medal: 2; Silver: 1: I-ENVEX 2013, Perlis. Gold Medal: ITEX, 2013, KL. Silver Medal: III EXPO 2013, Macau. Gold Medal: 2; Platinum Spesific Award: IBIS 2013, London. Gold Medal: 1; WIIPA Award: INOVA 2013, Zagreb.

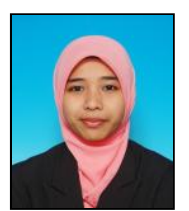

Fatimah A. Misebah was born on 12 October, 1989, in Selangor, Malaysia. She obtained B. Chem. Eng (biotechnology) from Faculty of Chemical and Natural Resources Engineering, University of Malaysia Pahang (UMP), and nowadays she is post-grade students of Chemical Engineering, University of Malaysia Pahang, Gambang, Kuantan, Pahang, Malaysia. Misebah has been focusing in research area of the biofuel energy, kinetics and catalysis, and biolubricant. She has appointed as research asisstant in the field of biotechnology.

Ms. Misebah has been a member of IEM and played a role in the post-grade sudent activity of UMP. This active student and exhibitor is awarded 3 Silver Medal, CITREX 2013 \&2014, Kuantan, Silver: WaterInno,WM, 2013, KL. 